\title{
Relationship between Knowledge Management Process and Creativity among Faculty Members in the University
}

\author{
Hamid Rahimi, Azizollah Arbabisarjou, \\ Sayeed Mohsen Allameh, and Razieh Aghababaei \\ University of Isfahan, Isfahan, Iran
}

\author{
hamid rahimi1982@yahoo.com; arbabisarjou2007@gmail.com; \\ dr allameh@ase.ui.ac.ir
}

\begin{abstract}
The recognition of knowledge and creativity as key strategic assets are very popular today. The purpose of this research was to study the relationship between Knowledge Management (KM) process and creativity among faculty members in the University. The research hypotheses were examined while considering KM process dimensions including Socialization, Combination, Externalization, and Internalization (SECI) and creativity based on demographic variables (age, gender, field of study, and employment status). This study was conducted using the correlation method. The statistical population consisted of 491 faculty members in the University of Isfahan from the year 2009 till 2010; from the 491, 85 were chosen by using stratified randomized sampling. The information gathering tools were researcher-made KM process Questionnaire with 26 items and Creativity Questionnaire with 23 items. 100 questionnaires were distributed to targeted population. Out of 100 questionnaires we received 85 completed questionnaires. This represents a response rate is quite suitable for this type of study. The results indicate that there is a positive and significant relationship between KM process dimensions and creativity. In addition, there is no significant difference between faculty members' KM process considering the variables of age, gender, and field of study, besides there is no significant difference among faculty members' creativity considering age, field of study, and employment status.
\end{abstract}

Keywords: KM process, SECI, Creativity, University, Faculty members

\section{Introduction}

Organizations in the current economy recognize knowledge as a key economic resource and, therefore, it is considered important for sustaining competitive advantage. Needless to say, organizations must possess the right knowledge in the desired form and content under all circumstances to be successful. The risks and uncertainties inherent in such dynamic environments have increased the importance of managing organizational knowledge (Paiva \& Fensterseifer, 2002).

Material published as part of this publication, either on-line or in print, is copyrighted by the Informing Science Institute. Permission to make digital or paper copy of part or all of these works for personal or classroom use is granted without fee provided that the copies are not made or distributed for profit or commercial advantage AND that copies 1) bear this notice in full and 2) give the full citation on the first page. It is permissible to abstract these works so long as credit is given. To copy in all other cases or to republish or to post on a server or to redistribute to lists requires specific permission and payment of a fee. Contact Publisher@InformingScience.org to request redistribution permission.
Various empirical and theoretical evidences have proven knowledge management (KM) to be a key source of competitive advantage and subsequently leading to organizational success. If any organization can recognize and control environmental factors (for example, competitors, stakeholders, technology, etc), then it can continue to exist much better. However, due to scientific and technological developments, the current 
organizational environment is more unstable and sophisticated, and the survival of the organization is threatened. In these circumstances, the organization is successful in improving and enhancing backgrounds of organizational \& individual growth, motivation, and creativity, whilst gaining knowledge, maintaining its life. This paper firstly presents a recapitulation of the definitions of KM \& creativity, followed by a description of some issues in KM \& creativity. It then provides an extensive review of the literature in order to identify a list of KM \& creativity outcomes. Based on the review, key dimensions or categories of KM are proposed and discussed. Following this, the paper presents the results of studies conducted to explore and examine the proposed outcomes. Finally, the paper culminates with a discussion on the research findings and suggestions for future research work.

\section{Literature Review}

\section{KM Process}

It is said that the concept of KM emerged from the concept of the learning organization. The concept of the learning organization was first introduced by Peter Senge (1995) through his work titled the Fifth Discipline. His work not only had great influence on KM, it also created a new paradigm for organization management theory (Cullen, 2001). However, recent survey evidences have shown that, while many organizations are claiming to have implemented KM, not many of them are considered to be successful in their KM efforts. Although KM has been acknowledged to improve organizational performance, there are no well-developed performance measures within the organizations surveyed to assess the value of their knowledge assets (Longbottom \& Chourides, 2001). KM implementation is an investment that needs resources and it requires efforts to measure its results. Without measurable success, enthusiasm and support for KM is unlikely to continue (Ranjit, 2004).

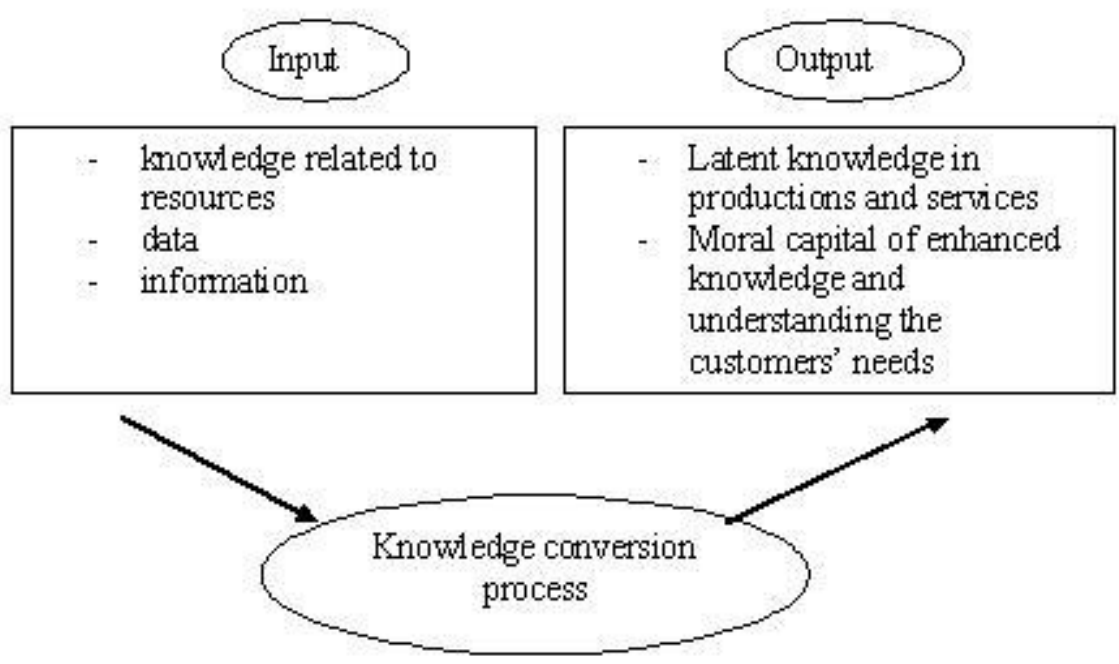

Fig 1: knowledge management process Zhao \& Bnar 2001 
$\mathrm{KM}$ involves various issues in the world of management, and this attitude is due to the transforming and moving of economic and productive systems to knowledge-based communities. In this attitude, knowledge is considered as an asset along with other resources such as land, occupation, and capital (Nonaka, 2006). KM process should be considered as an integrated management design, which focuses on strategic goals, follows the business processes, and applies the information technology. KM is related to a view advancing the organization goals by exploring and enhancing the asset of an organization, i.e., knowledge. The knowledge that is managed includes both explicit and tacit (mental knowledge of people) (Davenport, 1998). Functional process of KM process can be considered as a cycle of input-output as any other system, as shown in Figure 1. The process clearly indicates that knowledge management takes information, knowledge, and people as its basic inputs, and applied knowledge and intellectual capital as its desired outputs. KM emphasizes knowledge creation, transfer and embedding to serve different organizational purposes.

KM tries to gather, form, maintain, and distribute knowledge. Effective KM requires a continuous knowledge conversion process. Nonaka (2006) divides the KM process into four modes.

a) Socialization (tacit to tacit): the first phase of the KM process is sharing and distributing the ideas and the interaction of tacit knowledge with tacit knowledge. It is the same event that occurs during the dynamics of effective teams or between colleagues with common ideas. In this phase, the members discuss about what is more important and use the others' thoughts. The socialization is also known as converting new knowledge through shared experiences. Organizations gain new knowledge from outside their boundaries such as interacting with customers, suppliers and stack holders. This occurs in traditional environments where the son learns the technique of wood craft from his father by working with him (rather than from reading from books or manuals).

b) Externalization (tacit to explicit): This process focuses on tacit to explicit knowledge linking. Externalization requires the expression of tacit knowledge and its translation into comprehensible forms that can be understood by others. In a team climate, metaphors and allegories assist the individuals to externalize their own tacit knowledge (personal experiences, ideas, beliefs, and so on) and imagine a clear picture of others' ideas. It helps in creating new knowledge as tacit knowledge comes out of its boundary and becomes collective group knowledge. In this process we can say that knowledge is crystallized. The process of externalization is often driven by metaphor analogy and models. Quality circles are formed in manufacturing sectors where workmen put their learning and experience they have had to improve or solve the process related problems.

c) Combination: Here, the explicit knowledge, in the form of different collections of knowledge, already exchanged, distributed, and documented or discussed during meetings and sessions, is processed and categorized in order to create new knowledge. It is easily documented and distributed, when the knowledge is explicit and evident.

d) Internalization (explicit to tacit): Internalization involves the process of converting the explicit knowledge to tacit knowledge. Internalizing these ideas is effective in creating an understanding and developing a learning culture (learning through action). When this tacit knowledge is read or practiced by individuals then it broadens the learning spiral of knowledge creation. The organization tries to innovate or learn when this new knowledge is shared in socialization process. Organizations provide training programs for their employees at different stages of their working with the company. By reading these training manuals and documents employees internalize the tacit knowledge and try to create new knowledge after the internalization process.

Socialization is converting tacit knowledge to tacit knowledge by face-to-face communication or shared experience. Externalization is converting the tacit knowledge to explicit knowledge by 
developing concepts to embed the combined tacit knowledge. Internalization is converting the explicit knowledge to tacit knowledge and Combination is converting the explicit knowledge to explicit knowledge. These conversion processes are interacting in the spiral of knowledge creation.

Techniques to support creativity are software tools based on KM, including artificial intelligence models, idea processing, and information systems. These tools are used with the aim of creativity generation and promotion. KM can help to promote creativity and can be seen as the application to produce new knowledge, thus for our purpose, we argue that the KM is the basic activity for creativity.

\section{Creativity}

Creating, from a psychological point of view, refers to the production of something unique from other things. In other words, creation means reducing or enhancing a phenomenon and transforming and combining it with other phenomena, objects, or things. Creativity refers to the phenomenon whereby a person creates something new (a product, a solution, a work of art, etc.) that has some kind of value (Pir Khaaefi, 1999). Theoreticians such as Guilford (1989) believe that creativity is the tendency to generate or recognize ideas, alternatives, or possibilities that may be useful in solving problems, communicating with others, and entertaining ourselves and others (Feldman, 1990).

Creativity is a desired behavior in the organization that is valued by the organization and may even be rewarded (Baer \& Oldham, 2006). Creativity is identical to problem solving, which emerges in various artistic, scientific, and social forms (Aghaee Fishani, 1999). Weisberg (1986) proposes that creativity can be defined by the novel use of tools to solve problems or novel problem solving. In addition to this property, the element of helpfulness is important for creativity, because innovation without helpfulness would have no value. Therefore, it can be concluded from all viewpoints that creativity means to produce a unique and new phenomenon that resulted in solving scientific, industrial, and social issues. Creativity is the bringing into being of something which did not exist before, either as a product, a process or a thought.

\section{Relationship between KM Process and Creativity}

KM seems to be a critical factor in the success of any organization. Successful organizations have the capacity to absorb creativity into the organization and management processes. The basic elements of KM (socialization, internalization, combination, \& externalization) influence creativity in an organization. As knowledge organizations, institutions of higher education focus their major activities on learning, creating, and publishing knowledge. Universities as educational institutes are devoted to major knowledge activities. Therefore, it is necessary to highlight the place of KM in the higher education system and then use the theory of KM to find a trend to coordinate activities related to the processes of conversion and production of knowledge and thereby demonstrate the value of mental capitals for active and continuous existence in society (Rowely, 2000). That knowledge is a key component of all forms of creativity and is a widely accepted principle of modern innovation management (Chapman \& Magnusson, 2006). Knowledge is more and more regarded as a vital asset and the main source of the competitive advantage of a university. There is no simple, generally accepted definition of knowledge. The epistemology has also changed from a monist view to the pluralist one. Knowledge is different from data and information, but related to both of them. Unlike data and information, knowledge emerges from human interpretations and their complex interactions (Stacey, 2000). Organizational knowledge creation can be viewed as an upward spiral process from the individual level to the collective group level, and then to the organizational level, sometimes to the interorganizational level. Creativity is at the base of problem solving. 
For creativity to occur, knowledge must not just be shared, but also be used and recombined. Sometimes, the distinctions between knowledge creation and usage seem to be especially obscure, when facing complex systems such as creativity.

Creativity is a result of the combination of existing knowledge and new knowledge (Kogut \& Zander, 1992). The recombination of new and existing knowledge relies heavily on knowledge creation and use. In the next generation of KM, the importance of knowledge creation and usage has been substantially argued for value creation, and they become crucial factors in the creativity process. Placing knowledge creation and knowledge usage in the meta-model of KM for creativity is based on the following considerations:

- The creation/usage is two activities so closely related that one can not present without the other.

- In the creativity process, the two activities reciprocally function as cause and effect, which form a spiral creativity of knowledge.

-The natures of the two activities are different for creativity. For knowledge creation, the creativity of human beings and the heterogeneity, tacit and specialization of knowledge are keys for the novelty of creativity; for knowledge use, the harmony amongst users and the shared understanding, codifiability and diversity of knowledge are important for the success of creativity.

\section{Related \& Similar Research}

In obtaining the results and summaries of performed studies in Iran and other countries about the creativity of faculty members and its relationship with major components of KM process, no research having the same subject with this study was found. So the abstracts of relatively the same studies are presented here.

Martins (2000) in his research titled "Relationship between organizational culture and creativity" found certain environmental circumstances, strategic approaches, the values and actions of top management, organizational structure, and technological cycles can be associated in the following ways with organizational cultures that support creativity:

- External environment (e.g., economy and competitiveness encourage continual changes in products, technology and customer preferences).

- Reaction to critical incidents outside and within the organization, which is reflected in the strategy (e.g., innovation strategy) of the organization.

- Managers' values and beliefs (e.g., free exchange of information, open questioning, supports for change and diversity of beliefs).

- The structure of the organization, which in turn allows management to reach organizational goals (e.g., flexible structure characterized by decentralization, shared decision making, low to moderate use of formal rules and regulations, broadly defined job responsibilities and flexible authority structure with fewer levels in the hierarchy).

- Technology, which includes knowledge of individuals and availability of facilities (e.g., computers, Internet) to support the creative process.

Gholy Zadeh (2005) in his study titled "The rate of KM process and organizational culture in the university" demonstrated that Internalization in the realm of KM process has the highest place in the university, and after that, in descending order, are Socialization, Externalization, and Combination. Also, the results showed that there is a significant relationship between the organizational 
culture and Internalization, Externalization, and Combination, whilst this relation is not significant with Socialization.

Halawi (2005) titled his doctoral thesis "KMS success in knowledge-based organizations. The purpose of Halawi's study was to develop a model to assess the success of KMS in knowledgebased organizations. The results showed that this model has the potential to be used in studying the future of KMS.

Hall (2005) wrote in a paper titled "KM in various periods: Exchanging explicit and tacit knowledge" found importance and the challenges of KM in the periods of vast changes. The main purpose of this research is to assess KM in the periods of vast changes in the organization by analyzing the effect of integrating the KM into services and hygiene agencies in Texas. The findings have both theoretical and operational applications in information technology, KM, and project management.

Research was performed by Kangas (2006) and presented in his doctoral thesis titled "The relationship between organizational culture and innovations in knowledge management". The finding showed that KM may be considered as an effective and strategic innovation in organizational culture, which may lead to long term success, expansion of values, and enhancement of competitive profits of organizations.

In his doctoral thesis titled "Implementing KM to support executive decision making in a joint military Environment," Ward (2006) presented a qualitative and quantitative methodology to analyze the data. The results showed that innovations in KM do not manage knowledge directly. Instead, innovations of knowledge management manage the internal and external environment of the organization to promote the distribution of knowledge in order to create new knowledge by effective delivery of knowledge to decision makers.

Relationships between job resources and creativity still show variability across studies and, therefore, researchers have called for research on person-context interactions (Shalley, Zhou, \& Oldham, 2007). Numerous studies found a positive relationship between support for creativity and creativity, whereas other studies failed to support this relationship (Shalley et al., 2004). Results from the two meta-analyses on creativity showed an overall positive relationship between support for creativity and creativity (Eder \& Sawyer, 2007; Harrison, 2006).

Knowledge and information are both at the base of creativity. Very frequently we are not aware of how much do we know or how much we can create because of lack of motivation, time, or tools to guide us in practicing creativity- Scientific research is oriented towards the development of creativity as an educational process. Techniques to support creativity are software tools based on knowledge management. These tools are used with the aim of creativity generation and promotion, breaking prefixed schemes, stimulating imagination and, depending on the method, improving the environment in which the creative idea is produced. In the university (or in any other organization) it is important to incorporate staff creativity in the organization of processes and strategies.

\section{Hypotheses}

$\mathrm{H} 1$ : There is a significant relationship between $\mathrm{KM}$ and the creativity of the faculty members.

$\mathrm{H} 2$ : There is a significant relationship between knowledge Socialization and the creativity of the faculty members.

H3: There is a significant relationship between knowledge Externalization and the creativity of the faculty members. 
H4: There is a significant relationship between knowledge Combination and the creativity of the faculty members.

H5: There is a significant relationship between knowledge Internalization and the creativity of the faculty members.

H6: There is a significant difference between KM process and creativity of faculty members in terms of demographic variables (age, gender, scientific degree, field of study, and employment status).

\section{Methodology}

This study was conducted using the correlation method. Correlation research method is the ability to prove a positive or negative correlation between two subjects (Dellavar, 2007). The statistical population consists of 491 individuals from the faculty members of University of Isfahan. The sample was selected by stratified randomized sampling proportional to the volume of 85 respondents.

Table 1: The sample of faculty members in the university

\begin{tabular}{|c|c|c|}
\hline College & population & sample \\
\hline Education & 47 & 8 \\
\hline Physical Education & 15 & 3 \\
\hline Foreign Languages & 49 & 8 \\
\hline Human Science & 99 & 17 \\
\hline Economic \& Official Affaires & 78 & 14 \\
\hline Science Basic & 131 & 23 \\
\hline Technical \& Engineering & 72 & 12 \\
\hline Total & 491 & 85 \\
\hline
\end{tabular}

The tools for gathering data was a researcher-made questionnaire for KM process with 26 items and creativity inquiry with 23 items based on Likert five-point scale $(5=$ strongly agree and $1=$ strongly disagree) (A copy of the questionnaire is in the Appendix). In total, 100 questionnaires were circulated to targeted population. Out of 100 questionnaires we received 85 completed questionnaires. This response rate is quite suitable for this type of study. By using Alpha Cronbach coefficient, reliability coefficients were obtained equal to 0.92 for researcher made KM process and 0.95 for creativity. Also, both questionnaires were confirmed by 10 faculty members and 19 experts in the university in terms of nominal and content validity. The analysis of the data was performed in two levels of descriptive (frequency, percentage, average, and standard deviation) and inferential level (correlation coefficient, ANOVAs and t-test), using SPSS statistical software. 


\section{Findings}

This section deals with the research findings, presented in Tables 2 through Table 5.

Table 2: Results from correlation coefficient of components of $\mathrm{KM}$ process and creativity of the faculty members

\begin{tabular}{|c|c|c|c|c|}
\hline hypotheses & variable & frequency & $r$ & Sig. \\
\hline$H 1$ & KM process and creativity & 85 & 0.34 & 0.001 \\
\hline$H 2$ & $\begin{array}{c}\text { knowledge Socialization and } \\
\text { Creativity }\end{array}$ & 85 & 0.40 & 0.001 \\
\hline$H 3$ & $\begin{array}{c}\text { knowledge Externalization } \\
\text { and Creativity }\end{array}$ & 85 & 0.65 & 0.014 \\
\hline$H 4$ & $\begin{array}{c}\text { knowledge Combination and } \\
\text { creativity }\end{array}$ & 85 & 0.17 & 0.001 \\
\hline$H 5$ & $\begin{array}{c}\text { knowledge Internalization } \\
\text { and Creativity }\end{array}$ & 85 & 0.70 & 0.001 \\
\hline
\end{tabular}

Analysis of the results related to $\mathrm{H} 1$ indicated that correlation coefficient between the KM process and creativity of the faculty members was significant at the level of $\mathrm{P} \leq 0.05$. The rate of relationship between two variables was $r=0.34$, indicating an average and direct correlation between these two variables. Also, the determination coefficient showed that about $12 \%$ of variance of scores is related to the components of KM process.

Analysis of the results from $\mathrm{H} 2$ indicated that the correlation coefficient between the knowledge Socialization and the rate of creativity was significant at the level of $\mathrm{P} \leq 0.05$. The rate of correlation between two variables was $r=0.40$, indicating a linear correlation between these variables. Also, the determination coefficient showed that Knowledge Socialization and the rate of creativity share about $16 \%$ of variance of scores.

By analyzing of the results from $\mathrm{H} 3$ it became clear that there was a significant relationship between the knowledge externalization and the rate of creativity at the level of $\mathrm{P} \leq 0.05$. According to the output of Pierson's correlation coefficient test, the value for $r$ was equal to 0.65 . And it indicates that these two variables have an average and direct correlation. Also, the determination coefficient showed that these two variables share $42 \%$ of variance of scores.

According to the analysis of results from $\mathrm{H} 4$, the relationship between knowledge combination and the rate of Creativity is 0.17 at level of $\mathrm{P} \leq 0.05$. Also, the determination coefficient showed that these two variables share $3 \%$ of variance of scores.

According to the analysis of results from the H5, the correlation coefficient between knowledge internalization and the rate of creativity is $r=0.70$ at level of $\mathrm{P} \leq 0.05$. So, there is a correlation between two variables. Also, the determination coefficient showed that these two variables share $49 \%$ of variance of scores. The condition of uncertainty of these parameters is unknown and nonmeasurable. 
Table 3: Regression coefficient of KM process and the Creativity

\begin{tabular}{|c|c|c|c|c|c|}
\hline \multirow{2}{*}{ Model } & \multicolumn{2}{|c|}{$\begin{array}{c}\text { Unstandardized } \\
\text { Coefficients }\end{array}$} & $\begin{array}{c}\text { Standardized } \\
\text { Coefficients }\end{array}$ & \multirow{2}{*}{$t$} & \\
\cline { 2 - 4 } & $B$ & $\begin{array}{c}\text { Std. } \\
\text { Error }\end{array}$ & Beta & & \\
\hline (Constant) & 183.162 & 24.546 & 0 & 7.462 & .000 \\
\hline socialization & .091 & .406 & .020 & .225 & .823 \\
\hline externalization & -.123 & .248 & -.041 & -.496 & .620 \\
\hline combination & -.241 & .244 & -.096 & -.988 & .325 \\
\hline internalization & -.496 & .268 & -.183 & -1.854 & .065 \\
\hline
\end{tabular}

The regression coefficient showed that internalization has an effective role in creativity. On the other hand by increasing internalization, the level of creativity would enhance.

Table 4: The categorical variable

\begin{tabular}{|c|c|c|c|c|}
\hline & source & Value label & Code & $N$ \\
\hline \multirow{10}{*}{ H6 } & \multirow[t]{2}{*}{ Gender } & male & 1 & 55 \\
\hline & & female & 2 & 30 \\
\hline & \multirow{2}{*}{$\begin{array}{c}\text { Employment } \\
\text { status }\end{array}$} & temporary & 1 & 22 \\
\hline & & formal & 2 & 63 \\
\hline & \multirow[t]{3}{*}{ Scientific degree } & assistant & 1 & 42 \\
\hline & & Associate & 2 & 28 \\
\hline & & professor & 3 & 15 \\
\hline & \multirow[t]{3}{*}{ Field of study } & Humanistic science & 1 & 50 \\
\hline & & Science & 2 & 23 \\
\hline & & Technical \& engineering & 3 & 12 \\
\hline
\end{tabular}


Table 5: ANOVA of KM process and the Creativity of the members of faculty in terms of demographic variables.

\begin{tabular}{|c|c|c|c|c|c|}
\hline Source & Variable & Mean square & $d f$ & $F$ & Sig. \\
\hline \multirow[t]{2}{*}{ Regression model } & $K M$ & 833.695 & 13 & 1.066 & .385 \\
\hline & creativity & 995.311 & 13 & 1.058 & .254 \\
\hline \multirow[t]{2}{*}{ constant } & $K M$ & 923423.77 & 1 & 1452.177 & .000 \\
\hline & creativity & 1123654.45 & 1 & 1152.163 & .000 \\
\hline \multirow[t]{2}{*}{ Scientific degree } & KM & 200.285 & 2 & 2.78 & 0.037 \\
\hline & creativity & 725.162 & 2 & 3.3 & 0.028 \\
\hline \multirow[t]{2}{*}{ gender } & $K M$ & 463.11 & 1 & 1.08 & 0.42 \\
\hline & creativity & 395.56 & 1 & 2.69 & 0.001 \\
\hline \multirow[t]{2}{*}{ Employment status } & $K M$ & 1230.63 & 1 & 3.07 & 0.017 \\
\hline & creativity & 973.16 & 1 & 1.051 & 0.09 \\
\hline \multirow[t]{2}{*}{ Field of study } & KM & 1520.51 & 2 & 2.1 & 0.17 \\
\hline & creativity & 940.48 & 2 & 1.3 & 0.081 \\
\hline \multirow[t]{2}{*}{ Error } & KM & 1436.49 & 79 & & \\
\hline & creativity & 1648 & 79 & & \\
\hline \multirow[t]{2}{*}{ Total } & $K M$ & & 85 & & \\
\hline & creativity & & 85 & & \\
\hline
\end{tabular}

Purpose of error (MSW): mean of within group error

According to the obtained results from H6, the observed $\mathrm{F}$ did not show positive and significant difference among the means of the components of the KM process in terms of age, gender, and the field of study $(\mathrm{P} \leq 0.05)$. In other words, $\mathrm{KM}$ process of faculty members was equal in terms of gender and field of study. The observed $\mathrm{F}$ showed a positive and significant different among the components of the process of KM process in terms of the faculty members in terms of scientific degree (instructor, assistant professor, associated professor, full professor) and employment status $(\mathrm{P} \leq 0.05)$.

The observed $\mathrm{F}$ did not show significant difference among the means of the rate of creativity in terms of field of study and employment status ( $\mathrm{P} \leq 0.05$ in the university faculty members). In other words, the rate of creativity of the faculty members was equal in terms of field of study and employment status. According to the results, the observed F showed a significant difference among the means of the rate of creativity among faculty members in terms of scientific degree and gender $(\mathrm{P} \leq 0.05)$ in the university faculty members. In other words, the rate of creativity of the faculty members was not equal to their scientific degree. As the result showed that field of study and employment status are not considered important factors in the rate of creativity of the faculty members.

\section{Discussion}

The analysis of results from the first hypothesis showed that the correlation coefficient was significant between the socialization of knowledge and the rate of creativity at $\mathrm{P} \leq 0.05$. The rate of 
correlation between two variables was equal to $r=0.40$, indicating the linear correlation between these two variables. The determination coefficient also showed that $16 \%$ of variance of scores was common among the socialization of knowledge and the rate of creativity. The faculty members try to understand others' thoughts and personal information, the internal networks of organizations are used to exchange the professional information and data, and always a written summary of experiences and learnt points are proposed to the managers and administrators. The members exchange their personal and professional experiences both in team projects and across the independent research teams with each others.

The analysis of results from the second hypothesis showed that there was a significant relationship between the variables of externalization and the rate of creativity $(\mathrm{P} \leq 0.05)$. The value of $\mathrm{r}$ was equal to 0.65 , based on the output of Pearson correlation coefficient test, and it can be said that there is an average and direct correlation between these two variables. The determination coefficient also showed that these two variables share $42 \%$ of the variance of scores, indicating that the members tend to highlight their purposes by offering the objective instances; they often encourage each other to deliberate about their occupation and use the comparisons about their occupations to describe the concepts and are encouraged to use the net and databases to become familiar with their duties. According to the analysis of results from the third hypothesis, the relationship between knowledge Combination and creativity is 0.17 at $\mathrm{P} \leq 0.05$.

The determination coefficient also showed that the knowledge combination and the rate of creativity of the faculty members have $03 \%$ of variance of scores in common. These results show that the members have little time to think about what is discussed. They have fewer tendencies to organize ideas and results from the discussed subjects in formal sessions, and when they need the information, they do not know whom to ask.

The analysis of results related to the fourth hypothesis showed that the correlation coefficient between two variables, knowledge internalization and the rate of creativity, is $\mathrm{r}=0.70$ at $\mathrm{P} \leq 0.05$. So, there is a correlation between these two variables. The determination coefficient also showed that knowledge internalization and the rate of creativity share $49 \%$ of the variance of scores. The condition of uncertainty of these parameters is unknown and non-measurable. In the environment of the universities, when a problem occurs, personal experiences are used to solve it. The skilled individuals are encouraged to teach their skills and experiences to others and to cooperate with professionals in other fields, and the data and information are organized to support the decision making.

According to the results, the observed $\mathrm{F}$ at $\mathrm{P} \leq 0.05$ shows that there is not positive and significant difference between the means of components of KM process in terms of age, gender, and the field of study. In other words, organizational KM of the faculty members' university was equal in terms of age, gender, and field of study. The considered $\mathrm{F}$ shows a positive and significant different among KM process of the faculty members in terms of scientific degree (instructor, assistant professor, associated professor, professor) and employment status $(\mathrm{P} \leq 0.05)$.

The observed $\mathrm{F}$ at $\mathrm{P} \leq 0.05$ shows that there is not positive and significant difference among the means of the rate of creativity of the faculty members' university in terms of gender, the field of study, and employment status in the university faculty members. In other words, the rate of creativity is equal among the faculty members in terms of field of study and employment status.

The observed $\mathrm{F}$ at $\mathrm{P} \leq 0.05$ shows that there is not positive and significant difference among the means of the rate of creativity of the faculty members' university in terms of gender and scientific degree. In other words, the rate of creativity is not equal among the faculty members in terms of scientific degree. As the results show, it is clear that field of study and employment statuses are not considered as important factors in the rate of creativity of the faculty members. 
$\mathrm{KM}$, as an informed approach to developing, storing, retrieving, and distributing data and experiences, deals with the creativity in the organization. According to Nonaka (1995) directing personal knowledge along the organizational goals necessitates an environment based on sharing knowledge, exchanges, changes, and interaction among the members. Therefore, the success of an organization involves integration of all members. With an overview of the results of this study on the components of KM process and its relation with the rate of creativity of the faculty members' university, we can say that knowledge combination has the highest place in the domain of

KM process, which is followed by externalization, socialization, and internalization in descending order considering the high ratio of knowledge combination compared with internalization, the results indicated the high tendency of the faculty members to convert explicit knowledge to explicit knowledge rather than participating in the process of converting explicit knowledge to tacit knowledge. Also the high ratio of Externalization, compared with Internalization and Socialization, indicated that the faculty members tend more often to transform tacit knowledge to an explicit one and to reveal their own ideas, experiences, and information.

\section{Conclusion}

After reviewing the main tools and instruments for managing knowledge, technologically supported or not, this research provides recommendations so that universities could adopt the most appropriate KM strategy in alignment with their creativity. From the literature review, the present paper helps managers to diagnosis its KM implementation and implemented strategy in the organization and provides a summary of the evolution of KM process from different perspectives. The complete application of SECI models to an organization is not acceptable, but possible to apply partially. The KM implementation level is not so high. Also, it may be interesting to analyze organizations in different periods of time in order to observe their advances in KM and the existence of a KM implementation lifecycle. There are many factors, such as organization culture, language, competition, security, and confidentiality of data, influencing the successful application of SECI models. Our findings are based on a study of a single organization and, therefore, they may have limitations in their applicability in other settings. Although this study was challenged by various limitations, it enriches KM literature and sheds light on the importance of KM practices as a motivational factor for the creativity of faculty members. Practically, this study provides a guide for practitioners on how KM practices play a critical role in ensuring a quick and easy adjustment when organization circumstances change unexpectedly. Future research may focus on studying governance mechanisms that are practiced across organizations. Future studies may also focus on governance frameworks of knowledge sharing in the context of teams or groups from multiple organizations. Such research efforts would help promoting learning and, thereby, improving theory and practice of KM.

\section{References}

Aghaee Fishani, T. (1999). Creativity and innovation in human and organization. Tehran: Publication of Termeh.

Baer, M., \& Oldham, G. R. (2006). The curvilinear relation between experienced creative time pressure and creativity. Journal of Applied Psychology, 91(4), 963-970.

Chapman, R., \& Magnusson, M. (2006). Continuous innovation, performance and KM. Knowledge and Process Management, 13(3), 129-31.

Cullen, J. (2001). KM. Journal of the American Society for Information Science and Technology, 52(13), $1190-1192$.

Davenport, I. H. (1998). Working knowledge: How organizations manage what they know. Boston, MA: Harvard Business School Press. 
Dellavar, A. (2007). Research foundation in behavioral sciences. Tehran: publication of Doran.

Eder, P., \& Sawyer, J. E. (2007). A meta-analytic examination of employee creativity. Paper presented at the 22nd annual conference, society of industrial and organizational psychology (SIOP), New York, NY, April.

Feldman, R. (1990). Understanding psychology. Mc Graw Hill.

Gholy Zadeh, R. (2005). The rate of KM process and organizational culture in University of Mashhad Firdausi. Journal of Educational and Psychological Studies University of Mashhad, 4.

Guilford, J. P. (1989). Creative talents: Their nature, uses and development. Buffalo, NY: Bearly Ltd.

Halawi, L. (2005). KMS success in knowledge-based organizations: An empirical validation utilizing the Delone and McLean is success model. NOVA South Eastern University.

Hall, H. L. (2005). KM in various periods: Exchanging explicit and tacit knowledge. University of North Texas.

Harrison, M. (2006). A meta-analytic investigation of individual creativity and innovation. Paper presented at the 21s Annual Conference, Society of Industrial and Organizational Psychology (SIOP) Dallas, TX, April.

Kangas, A. (2006). The relationship between organizational culture and innovations in KM. International Journal of Educational Management, 12(3), 212-220.

Kogut, B., \& Zander, U. (1992). Knowledge of the firm, combinative capabilities, and the replication of technology. Organization Science, 3, 383-397.

Longbottom, D., \& Chourides, P. (2001). KM: a survey of leading UK companies. Proceedings of the Second MAAQE International Conference Versailles, France, 113-126.

Martins, E. C. (2000). Relationship between organizational culture and creativity. University of South Africa, Pretoria, MLNF dissertation.

Nonaka, I. (1995). The concept of 'Ba': Building a foundation for knowledge creation. California Management Review, 40(3), 40-54.

Nonaka, I. (2006). The knowledge creating company. London: Oxford University Press.

Paiva, E. L, \& Fensterseifer, J. E. (2002). Focusing information in manufacturing: KM perspective. Industrial Management \& Data Systems, 102(7), 31-39.

Pir Khaaefi, A. (1999). Creativity management and art set of research articles in management and art. Center of Studies and Art Research Minster of Islamic Culture.

Ranjit, B. (2004). KM metrics. Industrial Management \& Data Systems, 104(6), 457, 468.

Seif Hashemi, F. (2003).The relationship between philosophical attitude and managers' creativity in high school in Isfahan. University of Isfahan.

Senge, P. M. (1995). The fifth discipline: The art and practice of the learning organization. London: Century Business.

Shalley, C. E., Zhou, J., \& Oldham, G. R. (2007). The effects of personal and contextual characteristics on creativity. Journal of Management, 30(6), 933-958.

Stacey, R. D. (2000). The emergence of knowledge in organizations, emergence, 2, 23-39.

Ward, T. E. (2006). Implementing KM to support executive decision making in a joint military Environment. Capella University.

Weisberg, R. W. (1986). Creativity: Genius and other myths. New York: Freeman.

Zhao, F., \& Bryar, P. (2001). Integrating KM and TQM: A complementary process. Proceedings of the 6th International Conferences on ISO 9000 and TQM, UK. 


\section{Appendix}

\section{KM process questionnaires}

\begin{tabular}{|c|c|c|c|c|c|c|}
\hline \multicolumn{2}{|r|}{ items } & 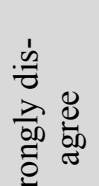 & 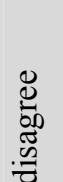 & $\begin{array}{l}\mathbb{8} \\
\stackrel{0}{0} \\
0 \\
z\end{array}$ & $\underset{\varpi}{\mathscr{\leftrightarrows}}$ & 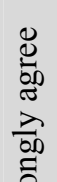 \\
\hline \multirow{5}{*}{ 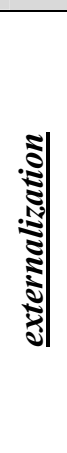 } & $\begin{array}{l}\text { 1) Staff is motivating to exchange thought and believes about their pro- } \\
\text { fession with each other. }\end{array}$ & & & & & \\
\hline & 2) Staff often has trends to clarify for others by objective samples. & & & & & \\
\hline & $\begin{array}{l}\text { 3) Staff often has trends to utilize example and simulation for subjective } \\
\text { and unclear concept. }\end{array}$ & & & & & \\
\hline & $\begin{array}{l}\text { 4) Staff offers their perception through technical and expert framework } \\
\text { with their staff for further understanding. }\end{array}$ & & & & & \\
\hline & $\begin{array}{l}\text { 5) In this organization, staff is encouraging to use network and web for } \\
\text { identifying tasks. }\end{array}$ & & & & & \\
\hline \multirow{11}{*}{ |: } & 6) Creativity and new thought are valued in this organization. & & & & & \\
\hline & $\begin{array}{l}\text { 7) The important and vital rules and standards are identified and stored } \\
\text { well. }\end{array}$ & & & & & \\
\hline & $\begin{array}{l}\text { 8) Staff use their individual experiences with new concept for more } \\
\text { understanding. }\end{array}$ & & & & & \\
\hline & $\begin{array}{l}\text { 9) Staff usually compares new concepts with their experience to further } \\
\text { understanding. }\end{array}$ & & & & & \\
\hline & $\begin{array}{l}\text { 10) Staff is encouraged to transfer their professional knowledge to less } \\
\text { experienced and new employees }\end{array}$ & & & & & \\
\hline & $\begin{array}{l}\text { 11) Staff collaborates with other interdisciplinary team through re- } \\
\text { search team. }\end{array}$ & & & & & \\
\hline & $\begin{array}{l}\text { 12) It emphasizes on development and entrepreneurship in this organi- } \\
\text { zation }\end{array}$ & & & & & \\
\hline & 13) Knowledge exchange with others helps to perform their work better. & & & & & \\
\hline & $\begin{array}{l}\text { 14) The information is organized clear and regular to support decision } \\
\text { making. }\end{array}$ & & & & & \\
\hline & 15) Staff has trends to share their individual information with others. & & & & & \\
\hline & $\begin{array}{l}\text { 16) It emphasizes on morale, Collaboration and participation, improve- } \\
\text { ment, in this organization. }\end{array}$ & & & & & \\
\hline \multirow{4}{*}{ 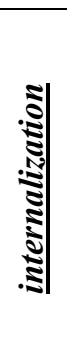 } & $\begin{array}{l}\text { 17- The obtained results are recorded and documented after formal evi- } \\
\text { dences. }\end{array}$ & & & & & \\
\hline & $\begin{array}{l}\text { 18) Staff is communicating with their colleagues if they have a fortune } \\
\text { to think about what discussed }\end{array}$ & & & & & \\
\hline & $\begin{array}{l}\text { 19) In this organization, discussed ideas and results organize during } \\
\text { formal meeting. }\end{array}$ & & & & & \\
\hline & 20) In this organization, the information is clear completely as needed. & & & & & \\
\hline
\end{tabular}




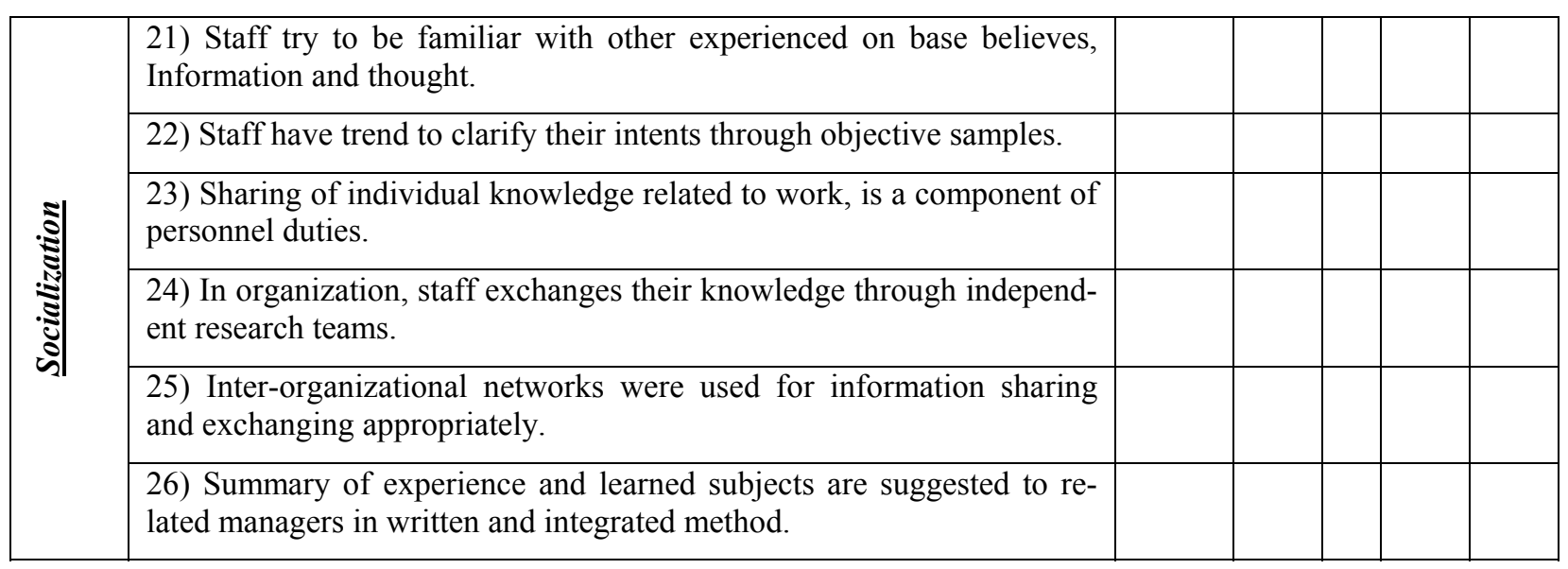

\section{Creativity Questionnaire}

\begin{tabular}{|c|c|c|c|c|c|}
\hline items & 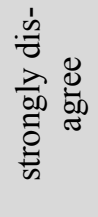 & 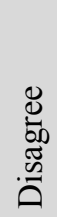 & $\begin{array}{l}\frac{\mathbb{J}}{\mathbb{Z}} \\
0 \\
0\end{array}$ & 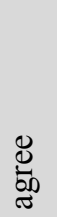 & 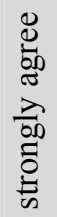 \\
\hline 1- I often find I get totally immersed in a creative idea. & & & & & \\
\hline 2- I am resourceful and can find the materials I need. & & & & & \\
\hline 3-I enjoy problem solving. & & & & & \\
\hline $\begin{array}{l}\text { 4-The meaning of a piece of work often evolves as I work } \\
\text { on it. }\end{array}$ & & & & & \\
\hline $\begin{array}{l}\text { 5-I don't reject ideas with initial faults but find ways to } \\
\text { make them work. }\end{array}$ & & & & & \\
\hline 6-I enjoy discovering new things. & & & & & \\
\hline 7-I have a sense of humor about my work. & & & & & \\
\hline 8-I can adapt my previous skills to suit an unfamiliar task. & & & & & \\
\hline $\begin{array}{l}\text { 9-I don't reject ideas with initial faults but find ways to } \\
\text { make them work. }\end{array}$ & & & & & \\
\hline 10-I can reflect back on my own work. & & & & & \\
\hline 11-I am happy to take a risk on an idea. & & & & & \\
\hline 12-I enjoy working as part of a creative team. & & & & & \\
\hline 13- I don't mind if ideas have more than one interpretation & & & & & \\
\hline $\begin{array}{l}\text { 14- I am interested in the aim or purpose of what I am do- } \\
\text { ing. }\end{array}$ & & & & & \\
\hline 15-I work persistently to complete a project. & & & & & \\
\hline 16- I find the energy and enthusiasm to research my ideas & & & & & \\
\hline
\end{tabular}




\begin{tabular}{|l|l|l|l|l|l|}
\hline 17-I find it easy to develop a strategy for a project. & & & & & \\
\hline 18-I am curious about the unknown & & & & & \\
\hline 19-Total score for Generating Ideas & & & & & \\
\hline 20-I like finding connections between things. & & & & & \\
\hline 21-I often have a strong vision for my projects & & & & & \\
\hline 22-My ideas can be odd or original. & & & & & \\
\hline $\begin{array}{l}\text { 23-I prefer to play with ideas rather than leap on the first } \\
\text { one }\end{array}$ & & & & & \\
\hline
\end{tabular}

\section{Biographies}

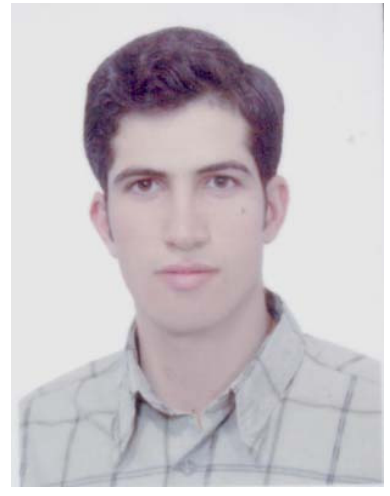

Mr. Hamid Rahimi is a full-time PhD Student, School of Educational Sciences \& Psychology, University of Isfahan. He teaches Educational Administration, Human Resources Management ( HRM), Organizational Behavior (OB), Organizational Development (OD) and research methodology in Educational Sciences for Bachelor and Master Students. He published a book named" Knowledge management in the Educational organizations" and an article about "Relationship Knowledge management and teaching-research performance" in Persian. Email: hamid rahimi 1982@yahoo.com,

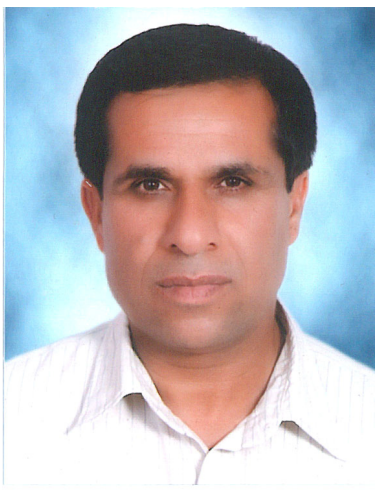

Mr. Azizollah Arbabisarjou is a full-time PhD Student, School of Educational Sciences \& Psychology, University of Isfahan. He teaches Educational Administration, research methodology in Educational Sciences, Educational psychology, principles of budgeting in education, Human relations in education for Bachelor students He published a book named" Management of Operation Room" in Persian. He is doing his $\mathrm{PhD}$ thesis about 360 degree feedback and chairpersons in the universities. Email: arbabisarjou2007@gmail.com 


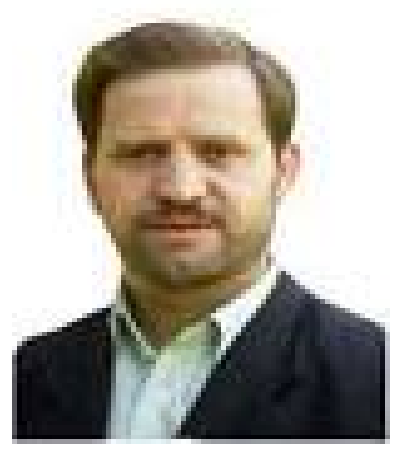

Dr. Sayeed Mohsen Allameh, $\mathrm{PhD}$, is a faculty member, School of Economics and official affaires, University of Isfahan. He is interested in Knowledge creation, knowledge management, Knowledge-based management, Human resources management. He teaches human relation management, Principles of Management organizational Behavior, Special English for management and MBA student and MIS and KM for PhD students. He holds many workshops for industries about Motivation, Human Relations, and Management in small industries, and entrepreneurship in industry and so on. He is guide and supervisor of Master thesis for Master student of Management, Economic Sciences,

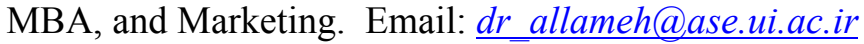

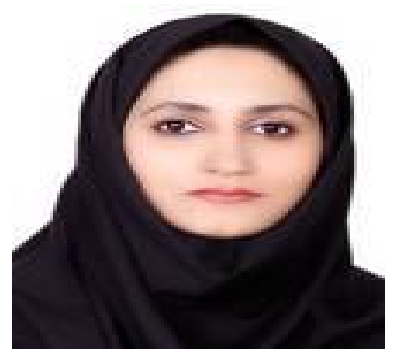

Mrs. Razieh Aghababaei has a master in educational administration and started her PhD program on September 2010 at School of Educational Sciences \& Psychology, University of Isfahan. She teaches Educational Administration, Human Resources Management (HRM), Organizational Behavior (OB), Organizational Development (OD) and research methodology in Educational Sciences for Bachelor and Master Student. She published an article about "Relationship self- leadership and creativity in faculty members" in Persian. 